\title{
A ALTERIDADE FEMININA
}

\author{
LA ALTERIDAD FEMENINA
}

Lourival Robty Santos de Souza*

\section{RESUMO}

A tradição filosófica, quando abordou a questão da existência da mulher, manteve seu olhar normativo e excludente, diferenciando o feminino do masculino, enquanto este último assumia o lugar de dominação, no topo da hierarquia. Este trabalho tem por objetivo apresentar os momentos em que essa perspectiva esteve presente nas reflexões filosóficas, desde o período clássico até o contemporâneo. Diante disso, surge o tema da alteridade em Levinas para ampliar a reflexão e propor uma maneira de evidenciar a presença da mulher em um meio de multirrelações. A alteridade se apresenta diante da realidade do mundo feminino sem a pretensão de descrever o modo do existir enquanto identidade, nem se opor ao mundo masculino, nem tampouco reafirmar as diferenças entre o binário homem-mulher. Fica claro que a proposta de Lévinas, sob a ótica deste trabalho, coloca a mulher em um lugar no qual o sistema totalizante e esgotador da racionalização não a alcança. Dessa maneira, o tema da alteridade da mulher se coloca como importante para tentar restaurar e restituir seu valor e, ainda mais, a sua humanidade que ficou submetida ao sujeito ideal masculino.

PALAVRAS-CHAVE: Alteridade. Feminino. Levinas.

\section{RESUMEN}

La tradición filosófica, cuando abordó la cuestión de la existencia de la mujer, mantuvo su mirada normativa y excluyente, diferenciando lo femenino de lo masculino, mientras que éste asumía el lugar de dominación, en la cima de la jerarquía. Este trabajo tiene por objetivo presentar los momentos en que esa perspectiva estuvo presente ante las reflexiones filosóficas, desde el período clásico hasta el contemporáneo. Ante esto, surge el tema de la alteridad en Levinas para ampliar la reflexión y proponer una manera de evidenciar la presencia de la mujer en un medio de múltiples relaciones. La alteridad se presenta ante la realidad del mundo femenino sin la pretensión de describir el modo de existir como identidad, ni oponerse al mundo masculino, ni tampoco reafirmar las diferencias entre el binario hombre-mujer. Es evidente que la propuesta de Lévinas, bajo la óptica de este trabajo, coloca a la mujer en un lugar en el que el sistema totalizante y agotador de la racionalización no la alcanza. De esta manera, el tema de la alteridad de la mujer se plantea como importante para intentar restaurar y restituir su valor, y aún más, su humanidad que quedó sujeta al sujeto ideal masculino. PALABRAS CLAVE: Alteridad. Femenina. Levinas.

\section{A ALTERIDADE FEMININA}

A tradição filosófica, quando abordou a questão da existência da mulher, manteve seu olhar normativo e excludente, diferenciando o feminino do masculino, enquanto este último

\footnotetext{
*Graduando em Filosofia pelo ISTA. E-mail: lourivalssouza16@gmail.com.
} 
assumia o lugar de dominação, no topo da hierarquia. Dessa maneira, "a hierarquia instala-se, pois um dos pares categoriais coloca-se como modelo a seguir enquanto o outro é visto como negação ou falha" (FERREIRA, 2007, p.139).

Dessa tradição filosófica, Platão, segundo Ferreira (2007), reservou à mulher a falta de privilégio, desvalorizando o ser da mulher, reduzindo-o à debilidade. A identidade feminina poderia apenas ter espaço no cenário social grego caso ela fosse capaz de imitar o ser do homem - condição impossível - pois o próprio filósofo grego ressaltou a inferioridade da alma feminina.

Em Aristóteles, o único lugar reservado para a existência feminina era na administração da própria casa. Esse mesmo filósofo ainda chega a afirmar a diferença entre o homem e a mulher pelos parâmetros corporais. "A alma é a forma do corpo. O corpo das mulheres é mais fraco, consequentemente a alma também o é. O critério passa por justificações biológicas como são a do calor, do frio ou da espessura dos fluidos" (FERREIRA, 2007, p.143).

Torna-se claro que a inferência de Aristóteles sobre a mulher é estreita e influenciada segundo o contexto no qual se encontrava a mulher. Aqui não há a pretensão de condenar o modo através do qual se pensou inicialmente, na tradição filosófica, o feminino, mas demonstrar que tais ideias formaram tendências preconceituosas acerca do horizonte feminino.

Além das mulheres, outros grupos também eram excluídos e inferiorizados,

Todavia, como qualquer historiador da Antiguidade o sabe, é recorrente a objeção do não especialista arguindo Atenas à exclusão dos escravos, das mulheres e dos estrangeiros. Respondendo, como se deve fazer para iluminar o debate, que a exclusão é diferente para cada uma dessas categorias - estrutural para os escravos, política, mas não social para as mulheres e para os estrangeiros [...] (CASSIN; LORAUX; PESCHANSKI, 1993, p. 14).

É importante perceber que mesmo excluída dos papéis políticos, restava à mulher a função social, mesmo que ainda mantida refém do padrão masculino. Ainda assim, como visto anteriormente, Aristóteles, manteve a casa como um lugar de poderio feminino, onde seria possível exercer um papel social, mesmo que esta função fosse secundária em relação aos papéis masculinos na conjuntura sócio-política grega.

Em Epicuro, a mulher tem o mesmo papel que os homens, o papel da reflexão. No Jardim epicurista todos eram convidados à reflexão em um ambiente que valorizava a 
amizade e a justiça. A filosofia epicurista mostrava-se avançada devido à permissão de homens e mulheres conviverem em um mesmo ambiente exercendo a mesma atividade, sem que um ganhasse mais destaque do que o outro; o importante no Jardim é filosofar diante da vida. Por isso Laurenti (2013, p. 585) destaca:

Por sorte existem ainda indivíduos assim, felizes. Talvez eles sejam os modelos a ser seguidos. Inspirados neles, precisamos criar um contexto à semelhança do Jardim de Epicuro, onde homens e mulheres filosofavam sob o calor da amizade, sendo regidos pelo valor da justiça.

De modo totalmente assimétrico, de acordo com Nietzsche, citado por Ferreira (2007, p.144):

\begin{abstract}
Nós, homens, desejaríamos que a mulher não continuasse a comprometer-se com explicações; pois foi por preocupação pelo homem e consideração à mulher que a igreja decretou: mulier taceat in ecclesia! Tal como foi para o bem da mulher que Napoleão deu a entender à célebre Madame de Stael: mulier taceat inpoliticis! E penso que é um verdadeiro amigo das mulheres aquele que diz às mulheres: mulier taceat de muliere!
\end{abstract}

A citação evidencia o menosprezo do filósofo em relação à capacidade de pensar e argumentar das mulheres. Ainda que Nietzsche tenha contribuído para a ideia de um novo homem, rompendo com os paradigmas sociais e filosóficos, ele nada acrescentou na promoção da causa feminina. Pelo contrário, ele apenas levou ao ridículo a capacidade de pensar, sugerindo que as mulheres ficassem confinadas a elas mesmas.

Esse modo de pensar restringe o despertar da alteridade e nega a validade da existência do ser da interação, o masculino e o feminino, por exemplo. Um não é a negação do outro, pelo contrário, ambos podem assumir suas alteridades, sem que uma comprometa a outra. Como já foi visto até aqui, a mulher era vista como aquela que não possuía condições suficientes para se destacar na sociedade e filosofia masculina. Com isso a mulher era a cópia imperfeita dos atributos masculinos.

Sendo uma cópia imperfeita do homem:

Essas cópias imperfeitas não eram, aliás definidas a partir delas mesmas, logo de uma subjetividade diferente, mas a partir da subjetividade ideal e em função de suas carências em relação àquela: idade, sexo, raça, cultura, etc. $\mathrm{O}$ modelo do sujeito permanecia único e os outros representavam exemplos inferiores, hierarquizados em relação o sujeito único. (SANTANA, 2006, p. 60). 
Conforme o trecho anterior, surge a seguinte pergunta: diante de parâmetros construídos pelos homens, como seria possível pensar e elaborar argumentos que ressaltassem a subjetividade feminina, se as próprias mulheres tiveram suas falas e seus modos de pensar negados? A essa questão este trabalho se proporá responder.

O único possuidor de uma alteridade, ou construtor de outras alteridades até então era o homem. A mulher surge descontextualizada do tema da alteridade, como algo secundário, colocada em regressiva subjetividade.

A questão do outro - que também diz respeito à subjetividade da mulher - não está bem colocada, por isso se recorre neste momento ao filósofo Emmanuel Levinas para discorrer sobre o tema. Desta forma, de acordo com Santana (2006), o outro é um substantivo utilizado para se referir tanto ao homem, quanto à mulher, mas que ao utilizar esse substantivo - o outro - falta esclarecer quem é esse outro ou quem ele representa, em uma relação de interação. A filosofia levinasiana procurou sair da imparcialidade referente a esse assunto e referir-se de modo pessoal e real.

Ora, entre os filósofos aqui citados, Levinas, mediante sua perspectiva fenomenológica, surge como o investigador capaz de negar a exclusão do outro (também mulher), por meio do conceito do rosto, preservando a subjetividade feminina, por exemplo, de ser reduzida a mais uma ideia.

Isso se justifica porque,

Na filosofia da alteridade, é impossível, mediante o olhar fenomenológico, transformar o rosto do outro em conteúdo. Desta forma, o rosto do outro é nu. O rosto expressa, exposto em sua fragilidade, uma mensagem pedagógica em que o eu é interpelado a ser justo e misericordioso. Levinas descreve o rosto do outro, em sua nudez e fragilidade, a partir da quadríade veterotestamentária: pobre, órfão, viúva e estrangeiro. Com efeito, Emmanuel Levinas conclui que do rosto nu, miserável e excluído do outro surge o apelo a uma responsabilidade indeclinável. (CHACON, 2015, p.19).

Torna-se possível incluir a subjetividade feminina como tema a ser investigado e incluso no pensamento filosófico, porque a conceito do rosto do outro abarca a condição de humanidade, do ser enquanto existente e não como abstração. O rosto do outro, retratado, por exemplo, na personagem bíblica da viúva, encontra-se nu, dado à vida, mas clemente por responsabilidade. 
Comumente pensa-se que a responsabilidade surge como uma escolha, no exercício da liberdade e, sendo assim, torna-se apenas resultado gerado por consequência de um ato intencional. Ou seja, a responsabilidade está inteiramente ligada à liberdade.

Em Lévinas é totalmente o contrário, ele compreende que não se é responsável mediante as próprias ações, mas frente ao outro que se relaciona com o "eu". Isso é o mesmo que dizer que o outro é quem nos alcança, isso significa que: "essa susceptibilidade designa uma não liberdade, e, de maneira paradoxal, é com base nessa susceptibilidade em relação a qual não temos escolha que nos tornamos responsáveis pelos outros" (BUTLER, 2017, p.116117).

Esse modo de pensar a alteridade rompe com o paradigma de que a liberdade é uma atitude da existência envolvida apenas por si mesmo, em que os outros são apenas os atingidos quando são interpelados. A alteridade propõe uma relação de responsabilidade, quando há a interpelação do rosto do outro, que invoca o ordenamento do cuidado.

Esse rosto é comunicativo, e impõe uma relação ética, na qual se é convidado a respondê-la, mesmo que para isso tenha-se que negar a própria liberdade. $\mathrm{O}$ ordenamento que o rosto faz se expressa na máxima: não matarás (BUTLER, 2017). No encontro entre duas pessoas, no face a face, o rosto aparece não como significado, ou conteúdo a ser explorado, como já foi dito de maneira diferente anteriormente, mas surge como epifania (aparição transcendente), ou como significação, e exatamente nesse momento o rosto "fala".

O “Tu não matarás” é a primeira palavra do rosto. Ora, é uma ordem. Há no aparecimento do rosto um mandamento, como se algum senhor me falasse. Apesar de tudo, ao mesmo tempo o rosto de outrem está nu; é o pobre por quem posso tudo e a quem devo tudo. E eu, que sou eu, mas enquanto primeira pessoa, sou aquele que encontra processos para responder ao apelo. (LEVINAS, 1982, p. 81).

Sendo assim, é possível retomar o apelo ao qual se detém este trabalho, pensar a mulher como um ser singular e existente diante de sua própria alteridade, que ficou confinada e inferiorizada nos processos históricos passados, como destaca Beauvoir (2002, p.179), quando afirma que "a história mostrou-nos que os homens detiveram todos os poderes concretos, desde os primeiros tempos do patriarcado, julgaram útil manter a mulher em estado de dependência; seus códigos estabeleceram-se contra ela; e assim foi que ela se constituiu concretamente como Outro".

Enquanto Lévinas articulou-se em inserir o outro como aquele que interpela e pede reponsabilidade ao "eu", Beauvoir atentou a mostrar que anterior à alteridade contemporânea, 
o Outro como mulher, esteve absolutamente outro, de maneira impessoal, estranhamente desconfigurada de sua existência na história, como algo que oferece perigo, tratado com espanto e reduzido ao totalmente diferente. O filósofo da ética da alteridade tenta reaproximar as humanidades estranhamente separadas pelos processos históricos, em que uma parece oferecer perigo à outra, colocando em xeque a possibilidade de coabitarem.

Quanto a essa coabitação, Foucault, ao tratar sobre os objetivos do casamento, por exemplo, destacou duas qualidades nesse estilo de vida: a primeira diz respeito à descendência que o casal deve conquistar, e a segunda sobre a vida a ser compartilhada.

A presença do outro, o face a face, a vida lado a lado, não são apresentados simplesmente como deveres, mas como uma aspiração característica do vínculo que deve reunir os esposos. Eles podem muito bem ter cada qual o seu papel; mas não poderiam privar-se um do outro. [...] O casamento deve ser da ordem da fusão total. [...] Quanto à ordem da fusão total, só os casamentos por amor, onde os esposos são ligados pelo amor, podem realizá-la. (FOUCAULT, 1995, p.161 et seq.).

Para tanto dá-se ênfase ao ápice da reflexão quando o filósofo afirma que para atingir o essencial de uma vida em comum é preciso desfazer-se da animalidade da relação, que esta constituição não poderá avançar se cada um olhar na própria direção, ou seja, é preciso abrirse para o universo do outro, àquilo que outrora lhe foi desconhecido, que é, de fato, ser humano em uma particularidade que rompe com o princípio do ensimesmamento (FOUCAULT, 1995).

Pensar na alteridade levinasiana é abrir-se à ideia de que o binário homem-mulher pode coexistir, sem que um tenha que assimilar a identidade do outro, ou invadir seus espaços. Existem em si, e falam-se de lugares diferentes, e isso é o que pode constituir o encontro face a face, a interpelação, ao invés de se negarem.

\footnotetext{
Com efeito, cada singularidade concreta não pode prescrever um ideal válido para todas e para todos, pois, para assegurar a coabitação entre os sujeitos, notadamente na cidade, um mínimo de universalidade é necessário. Para sair do modelo todopoderoso do um e do múltiplo, é preciso passar ao dois, um dois que não seja duas vezes o mesmo, nem um grande e um pequeno, mas dois realmente diferentes. (FERREIRA, 2006, p. 62).
}

A alteridade se apresenta diante da realidade do mundo feminino sem a pretensão de descrever o modo do existir enquanto identidade, nem se opor ao mundo masculino, nem tampouco reafirmar as diferenças entre o binário homem-mulher, mas para apresentar que esses sujeitos podem ser companheiros sem o medo de que diferente seja sinônimo de perigo, 
mas necessários diante de suas alteridades, pois a responsabilidade que lhes cabe diante do rosto do outro também os impele.

\begin{abstract}
Assim, pensar em tornar emergente o outro do mesmo, de recusar a ideia de ser reduzida a esse outro do mesmo, a um outro do um, a um ou uma outra do um, não para ele se tornar como ele, mas para constituir como sujeito autônomo e diferente, é preciso libertar antes de tudo o sujeito feminino do mundo do homem e admitir este escândalo filosófico: o sujeito não é mais um, nem único. (FERREIRA, 2006, p. 62).
\end{abstract}

O libertar-se um do outro significa acreditar na plenitude da ética como filosofia primeira, na qual a alteridade é estudada como alvorada do encontro do "eu e o outro", com relação de proximidade, em que as subjetividades são inauguradas por intermédio do encontro, e a alteridade demonstra-se como condição de simetria, em que a vivência do "eu e do outro" são experienciadas profundamente.

Neste momento pode-se entender que o homem, ou aquele que se representava como sujeito ideal, passa a considerar a ideia de que realmente a mulher teve seu processo de subjetividade e alteridade adiado, mas que ainda é possível ressignificar, pois segundo Marcondes Filho (2007, p.61), “o outro não pode ser conhecido como sendo uma variação de cada um de nós ou por projeção nossa dessas variações para fora de nós; há um acesso irredutível que leva ao tu, onde cada encontro cria uma nova história".

É sobre essa nova história que o horizonte da alteridade feminina surge, e seu rosto,

[...] é proximidade que não é sígnica, não remete a nenhum tema, mas que se apresenta apenas rastro de si mesmo, algo que me importuna, que não se iguala a mim. Ele é aproximação, diz Lévinas, não superável especulativamente, é a infinição ou a glória do Infinito, ele é um «estar em frente de» (nos dois sentidos que a língua francesa atribui ao en face) e nesse frente a frente o brilho da primeira racionalidade, das estruturas impessoais da razão, é o infinito que me falando a partir desse rosto. Rosto, assim, é proximidade porque vem do Infinito e o infinito, diz Lévinas, não se enclausura em nada desejável, nem em qualquer fim: ele o faz através de um rosto. (MARCONDES FILHO, 2007, p. 62).

Fica claro que a proposta de Lévinas, sob a ótica deste trabalho, coloca a mulher em um lugar no qual o sistema totalizante e esgotador de racionalização não a alcança. Desta maneira, o tema da alteridade da mulher se coloca com grande importância para tentar restaurar e restituir seu valor, e ainda mais, a sua humanidade que ficou sujeita ao sujeito ideal masculino.

Intencionalmente, toma-se a mulher como tema para restituir seu espaço, valorizando sua feminilidade, que é o elemento e a afirmação de sua inteira alteridade, não mais 
esquecida, mas afirmada e posta à vida e às discussões. "É a feminilidade como tal que introduz na civilização esse elemento outro, que é a verdade da vida e da poesia e que pode, só ele, libertar a humanidade. [...] Ela não tem outra vocação senão o amor, e isto não constitui inferioridade, porquanto a vocação do homem também é o amor" (BEAUVOIR, 2002, p. 283).

Apesar dos processos de negação na história, a mulher é capaz, por meio da ética da alteridade, transcender, expor seu rosto e deixar que ele mesmo cultive o amor nas relações interpessoais, nos tantos eu-tu.

A transcendência se dá porque a mulher conhece o outro gênero em seu corpo, ela o engendra, ela o vivencia internamente. Destaca-se uma característica que lhe é própria, mas ainda assim ela experimenta o avesso da alteridade levinasiana quando o outro a ressente, a descontrói, e volta seu olhar com resistência sufocando seus desejos e suas expressões. A transcendência da mulher está construída de maneira horizontal, numa vigorosa partilha de vida, que respeita o outro que a invade.

Por fim, cabe citar Maria de Mágdala, como personagem bíblica do segundo testamento, que viveu em sua carne o ser mulher, mas teve o privilégio de encontrar com Jesus após a sua morte, com ele ressuscitado. Ainda que tenha sido contestada por outros personagens bíblicos, chamados Pedro e André, tal contestação é a clareza de que a mulher teve seus pensamentos submissos ao do homem, mas mesmo assim é capaz de sobressair e integrar-se por sua sensibilidade.

Será possível que o Mestre tenha conversado assim com uma mulher, sobre segredos que nós mesmos ignoramos? Devemos mudar nossos hábitos; escutarmos esta mulher? Será que Ele verdadeiramente a escolheu e a preferiu a nós? [...] Pedro, tu sempre foste um irascível; vejo-te agora te encarniçar contra a mulher, como o fazem nossos adversários. Pois bem! Se o Mestre tornou-a digna, quem és tu para rejeitá-la? (MÁGDALA, 1998, p. 37 et seq.).

\section{Referências}

BEAUVOIR, Simone de. O segundo sexo: a experiência vivida. Rio de Janeiro: Nova Fronteira, 2002.

BUTLER, Judith. Relatar a si mesmo: crítica da violência ética. Belo Horizonte: Autêntica, 2015 .

CASSIN, Barbara; LORAUX, Nicole; PESCHANSKI, Catherine. Gregos, bárbaros, estrangeiros: a cidade e seus outros. Rio de Janeiro: Editora 34, 1993. 
CHACON, Daniel Ribeiro Almeida. Rosto e responsabilidade na filosofia da alteridade em Emmanuel Levinas. Intuitio, Porto Alegre, v. 8, n. 2, p. 15-24, dez. 2015. Disponível em: http://revistaseletronicas.pucrs.br/ojs/index.php/intuitio/article/view/19599. Acesso em: 08 set. 2018.

FERREIRA, Maria Luísa Ribeiro. A mulher como "o outro": a filosofia e a identidade feminina. Universidade de Lisboa, 2007. Disponível em:

http://ler.letras.up.pt/uploads/ficheiros/5612.pdf. Acesso em: 11 set. 2018.

FOUCALT, Michel. O cuidado de si. Rio de Janeiro: Graal. 4. ed. 1995.

LAURENTI, Carolina. Sobre pesquisadores felizes e infelizes. Psicologia em Estudo, Maringá, v. 18, n. 4, p. 583-586, out./dez. 2013. Disponível em:

http://www.scielo.br/pdf/pe/v18n4/01.pdf. Acesso em: 03 set. 2018.

LÉVINAS, Emmanuel. Ética e infinito. Lisboa: Edições 70, 1982.

MÁGDALA, Miriam de. O evangelho de Maria: evangelho copta do século II. Tradução e comentários de Jean-Yves Ieloup. Petrópolis: Vozes, 1998.

MARCONDES FILHO, Ciro. O outro como um mistério e o feminino como a alteridade absoluta: sobre a recuperação do face a face na comunicação em Emmanuel Lévinas.

Matrizes, USP, São Paulo, n. 1, p. 55-77, out. 2007. Disponível em: www.revistas.usp.br/matrizes/article/download/38177/40905/. Acesso em: 05 set. 2018.

SANTANA, Maria Angélica. A mulher em sua subjetividade no pensamento levinasiano. Último Andar, São Paulo, n. 15, 2006. Disponível em:

https://revistas.pucsp.br/index.php/ultimoandar/article/view/13183/9708. Acesso em: 14 set. 2018. 